\title{
Is there a future for the use of non-traditional placement settings for final year social work students?
}

\author{
Cathie Jasper ${ }^{1}$, Liz Munro², \\ Pauline Black ${ }^{1}$ and Hugh McLaughlin ${ }^{3}$
}

Abstract: This paper describes the development of a particular type of nontraditional placement setting for final year social work students: a 100 day, last practice placement based within Police Public Protection Investigation Units (PPIUs) through collaboration between the Police and Manchester Metropolitan University. It will evaluate the degree of progress made since these placements began in 2007 and consider some of the strengths and difficulties encountered in providing consistently good quality practice learning experiences for final year students within PPIU settings. The paper will summarise the learning gained from a recent evaluation of these placements and will describe some of the developments that have resulted from this evaluation.

This paper will also consider whether such non-traditional placement settings can continue to provide suitable practice learning opportunities for final year social work students in the light of the newly proposed placement criteria for final placements (TCSW, 2012a) and in the increasingly challenging climate for practice learning reflected in the continuing decreased availability of 'statutory' placements.

Keywords: practice learning; non-traditional placement setting; practice educator; placement criteria; Practice Educator Professional Standards; professional capabilities framework

1. Senior Lecturer in Social Work, Manchester Metropolitan University

2. Associate Lecturer in Social Work, Manchester Metropolitan University

3 Professor of Social Work, Manchester Metropolitan University

Address for correspondence: Dept of Social Work \& Social Change, Faculty of Health, Psychology \& Social Care, Manchester Metropolitan University,799 Wilmslow Road, Didsbury, Manchester, M20 2RR. c.jasper@mmu.ac.uk

Date of first (online) publication:

5 J. of Practice Teaching \& Learning 12(2), pp.5-25. DOI: 10.1921/5802120202. @ w\&b 
Cathie Jasper, Liz Munro, Pauline Black and Hugh McLaughlin

\section{Introduction}

This article aims to describe the development of non-traditional placement opportunities for final year social work students within Police Public Protection Investigation Units (PPIUs) in the North West of England and to summarise the findings from an online survey of the views of students, practice educators and on-site supervisors about their experiences of these placements. At a time of rapid and significant changes in practice education - including the introduction of nationally agreed Practice Educator Professional Standards (TCSW, 2012b); the need to develop holistic assessment criteria for practice learning that are consistent with the domains of the Professional Capabilities Framework (TCSW, 2012c) and the introduction of new practice learning guidance in respect of placement criteria (TCSW, 2012a), the implications of these changes in relation to the continued use of PPIU placements for social work students, are explored.

\section{Background}

The establishment of the new Social Work Degree in 2003 and the rapid increase in student social worker numbers alongside the increase in placement days to 'at least 200 days' (Department of Health 2002, p.3) necessitated the provision of a corresponding increase in practice learning settings and opportunities, particularly within 'non-traditional' settings (Doel, Deacon and Sawdon, 2007). A non-traditional setting can be defined as a placement setting where social work students are "not surrounded by professionals named as "social worker" ' (Hughes, 2009, p.22). Since this time, there has been a period of continuing and well documented support for the development of such non-traditional settings for practice learning on a local, regional and national basis (Doel et al., 2007; Doel, 2005; Billingham, 1999; Collins et al., 2010; Scholar et al., 2012).

For Manchester Metropolitan University (MMU), a Higher Education Institution (HEI) operating within the North West of England, there were significant additional local drivers that necessitated the expansion and development of social work student placements, particularly those within non-traditional settings. The low percentage of placements in statutory settings had been a longstanding concern within the North West and added a strong impetus to the ongoing development and support offered

6 J. of Practice Teaching \& Learning 12(2), pp.5-25. DOI: 10.1921/5802120202. @ w\&bb 
to placements within Police Public Protection Investigation Unit (PPIU) settings. The General Social Care Council (GSCC) annual reports regarding Social Work Education in England demonstrate that since 2006, the North West region has consistently had the least numbers of placements within the 'lower rate' or 'statutory' sector, falling to $42 \%$ of placements in 2008-9 (GSCC, 2009-10, p.39).

At MMU, undergraduate and postgraduate social work students undertake a 100 day last placement in their final year, during which they are required to provide evidence for the National Occupational Standards for Social Work - Key Roles 4, 5 and 6 (Key Role 4 - Manage risk to individuals, families, carers, groups, communities, self and colleagues; Key Role 5 Manage and be accountable, with supervision and support, for your own social work practice within your organisation; Key Role 6 - Demonstrate professional competence in social work practice, (Topss UK Partnership, 2002) along with evidence that they are meeting the standards from the General Social Care Council (GSCC) Code of Practice for Social Workers (GSCC, 2004).

Since 2007 (up to and including the academic year 2010-11), MMU have placed 22 final year BA and MA social work students within 7 different PPIUs for their 100 day placement. Within these placements, students have the opportunity to work within different sections of the PPIU: the Child Abuse Investigation unit, the Domestic Abuse unit, the Missing from Home unit and the Vulnerable Adults unit. The range of potential learning opportunities within these PPIU settings has included: preparing for, attending and presenting information at multi agency strategy and risk meetings; following up referrals with Local Authority Children's and Adults Services; undertaking Common Assessment Framework initial assessments (CAFs) and risk assessments; following up referrals to the PPIU where there is a low level of concern for welfare; liaising with other agencies regarding support and monitoring the provision of services; advising and supporting individuals regarding risk and safety planning and attending and contributing to child protection and adult safeguarding meetings. For some students, additional learning opportunities have also been provided outside the PPIU as part of the overall placement, through shadowing periods or attachments to Local Authority Children's and Adults Services, including Duty and Assessment teams and Adult Safeguarding Teams and spending time undertaking work with other agencies and multi disciplinary teams.

The PPIU placements were originally identified as being particularly

7 J. of Practice Teaching \& Learning 12(2), pp.5-25. DOI: 10.1921/5802120202. @ w\&b 
useful for final year students because of their links with other statutory agencies, thus providing students with an opportunity to have experience of 'statutory social work tasks involving legal interventions' (DoH, 2002, p.3) and as ideal placements for the demonstration of 'partnership working and information sharing across professional disciplines and agencies' (DoH, 2002, p.3). Maclean and Caffrey (2009) highlight such placements as demonstrating innovation in practice learning and note, in particular, the contribution that they make to inter-professional learning.

Similar schemes within police and PPIU settings have been also developed and evaluated elsewhere (Hek, 2012, Roberts and McMillan, 2008, Miller, 2007). Many of the findings relating to such placements both benefits and 'problems'- were replicated within our own experience of developing and sustaining these PPIU placements. Such placements require detailed planning and preparatory work at the initial stages as well as ongoing liaison and involvement with police personnel, helping to promote ownership of such schemes (Hek, 2012). We have benefitted from continuing high level strategic support from within the Police, in the form of a senior officer who was an on-site supervisor for the first social work student placed within a PPIU in 2007, and who has continued to be a committed advocate for the scheme. Research has noted the benefits of having an 'identified champion' (Roberts and McMillan 2008, p.24) within the police who can both 'speak the local language' (Doel, 2005, p.22) and who is clearly identified as a point of reference.

We have worked alongside the police to develop the scheme and respond to differing student issues as they have arisen. This has included giving information to students about the nature of the placements and work available within the PPIU; inviting previous final year PPIU students and on-site supervisors in to talk with students; 'matching' students and suitably qualified and experienced off site practice educators to individual PPIU placements and the provision of a 2 day PPIU on-site supervisor course. However, whilst improvements to the scheme have been made, anecdotal reports from students, tutors and practice educators suggested there were on-going issues that needed to be addressed. An attempt was therefore made to capture these issues more comprehensively through undertaking a stakeholder evaluation that sought the views of the students, on-site supervisors and off-site practice educators involved in PPIU placements.

8 J. of Practice Teaching \& Learning 12(2), pp.5-25. DOI: 10.1921/5802120202. @ w\&bb 
Is there a future for the use of non-traditional placement settings in social work?

\section{Evaluation}

A small-scale survey of the 22 social work student placements within 7 different PPIU settings was therefore undertaken. In response to an invitation email sent out to students, off-site practice educators and on-site supervisors, 9 students completed an online semi-structured questionnaire along with 3 on-site supervisors and 5 practice educators (who completed questionnaires in respect of 8 of the 22 student placements - as some practice educators supervised more than 1 PPIU placement). Responses were received in relation to 6 of the 7 PPIU placement settings. The survey included questions that aimed to elicit responses across a range of issues relevant to final year placements settings such as: the relevance and usefulness of the preparation currently provided prior to the start of the placement; induction; the understanding of the social work student role on placement and availability and suitability of learning opportunities to meet Key Roles 4-6 of the National Occupational Standards for Social Work (Topss UK Partnership, 2002). Students, on-site supervisors and practice educators were asked what positive benefits or areas of improvement they could identify in respect of the placement. Feedback was additionally sought about the frequency and usefulness of supervision and the availability of learning opportunities to meet the GSCC Codes of Practice. However, these latter two issues are not considered in the current article, although these may be areas for future discussion. The relevant ethical permission was also sought and received from MMU's Faculty Academic Ethics Committee.

\section{Methodology, analysis and findings}

A purposive sampling method was used (Bryman, 2008) as it was felt that seeking the views of the students, practice educators and on-site supervisor directly involved with these placements, was the best way to find out how well these PPIU placement settings were working in practice. Whilst it is accepted that this approach therefore limits the degree to which the survey's findings can be generalised (Orme and Shemmings, 2010) either to other PPIU placements or indeed, to other non- traditional placement settings, it is felt nonetheless that the findings may still be a useful addition to the limited range of evaluative research conducted in this area (see for example, Hek, 2012; Roberts and McMillan, 2008; Miller, 2007).

9 J. of Practice Teaching \& Learning 12(2), pp.5-25. DOI: 10.1921/5802120202. @ w\&bb 
The online survey utilized a semi- structured, self-completion questionnaire to obtain information about the quality of PPIU placements in relation to a series of predetermined areas. Consequently, elements of a deductive approach (Braun and Clarke, 2006) were evident in the selection and initial coding of some of the themes during the process of analysing the data; especially the themes of preparation for placement; induction; role perception and the availability and suitability of learning opportunities in relation to Key Roles 4-6. However, within these initial parameters, a more inductive approach (Braun and Clarke, 2006) was used to analyse the data in more detail, especially through the iterative process of examining the range of differing responses provided and seeing what latent issues emerged as being important, in relation these key themes. The response rates to the questionnaires are outlined below, in Table 1 .

Table 1

Questionnaire Response rate

\begin{tabular}{lccc}
\hline Respondents & Number & \multicolumn{2}{c}{ Response rate } \\
\hline Students & originally contacted & $\mathrm{n}$ & $\%$ \\
Practice educators & 22 & 9 & 41 \\
On-site supervisors & $10^{1}$ & 8 & 36 \\
\hline
\end{tabular}

1. The number of practice educators contacted was 10 rather than 22 , as several practice educators supervised more than one PPIU placement. Practice educators were asked to complete a questionnaire in respect of each individual placement).

In relation to triangulation of the responses (Bell, 1993), a range of different sources of data were received in relation to 6 of the 7 PPIU sites. All 8 of the practice educator responses related to the same 5 PPIU placement settings for which student feedback was also received. 2 of the 3 on-site supervisor responses also related to same 5 PPIU settings. However, the 3rd on-site supervisor response related to a separate PPIU site for which no student or practice educator responses were received.

The students who participated in our evaluation study made a number of positive evaluative statements about their placements in PPIUs - the variety of work available; the supportive team environment; learning about the work of the PPIU and experiencing the way the police work in partnership with other agencies and, in particular, the opportunity to understand

10 J. of Practice Teaching \& Learning 12(2), pp.5-25. DOI: 10.1921/5802120202. @ $w \& b b$ 
Is there a future for the use of non-traditional placement settings in social work?

the work of the PPIU (and relevant procedures, such as child protection procedures) from a police perspective.

Ilearnt how the organisation works and did a lot of multiagency working (student 7).

... learning about the police role in the community and how they interact with social services and other agencies (student 3).

Understanding child protection procedures from a police point of view (student 6).

These perceived benefits, particularly in helping students to enhance their understanding of multi-disciplinary perspectives and ways of working, are echoed elsewhere (Hek, 2012; Roberts and McMillan, 2008). More generally, the positive impact of placements outside 'traditional' social work settings in promoting inter professional learning and working has been clearly documented (Wilson and Hillison, 2005). Other benefits of non-traditional placements have included increasing student awareness of different professional roles and responsibilities (Gregson and Fielding, 2008); increasing confidence and understanding of a social work professional identity (Hughes, 2009); providing opportunities for direct work with service users and to experience 'real social work' (Scholar et al., 2012) and allowing students the opportunity to develop creative, flexible, and sometimes much more autonomous and self-directed ways of working (Barron, 2004).

However, the analysis of the PPIU questionnaire responses confirmed a mixed and complex picture, indicating the presence of a number of variables affecting the student experience. However, it was possible to identify and cluster some key issues arising from the responses. These were:

- The importance of the preparation and induction phases of the placement in developing a good level of shared knowledge and understanding of the role of the student and of the on-site supervisor.

- The importance of developing a shared understanding of the social work role and the impact this had on the experience of placement

- The importance of identifying suitable learning opportunities to meet each relevant Key Role, including the need to negotiate for additional learning opportunities to be provided outside the PPIU when the learning requirements could not be met within the PPIU setting alone.

11 J. of Practice Teaching \& Learning 12(2), pp.5-25. DOI: 10.1921/5802120202. @ w\&b 


\section{Preparation for placement and induction}

All social work students considered for a placement with the PPIU completed an informal visit to the placement agency, prior to final confirmation of a placement offer with the PPIU. The students generally found this visit to be useful in preparing them for their placement.

The informal visit provided me with useful information about the teams within the PPIU and what work they do, the roles and responsibilities of the teams (student 5).

I was given lots of information about the teams located within the PPIU and the nature of the work (student 4).

However, 4 students expressed the wish that they had been given more specific information about the PPIU setting at this stage, about what their role would be and how the work of the agency could fulfil their Key Role requirements.

...the scope of the work the agency carries out was discussed only briefly... support was not discussed...opportunities for me to fulfil my key roles were only discussed very briefly (student 2).

Students generally found the information contained in the university placement handbook to be useful in terms of outlining the learning requirements for last placements. Several students though noted that they would have liked to have received more specific information from the university about PPIU placements.

...handbook was quite general. It needed to be geared specifically for my placement as it was quite different to the others, following more than just social work guidelines and codes of practice, I had to follow the police procedures and policies too (student 9).

By the time the placement agreement was held however, the majority of students were confident that the PPIU placement would enable them to meet their learning outcome requirements for final placement.

In relation to the process of induction, the feedback suggested induction was sometimes patchy and inconsistently experienced by students. Having the opportunity to meet with or 'shadow' key PPIU team members and the members of other partner agencies was perceived as extremely helpful in

12 J. of Practice Teaching \& Learning 12(2), pp.5-25. DOI: 10.1921/5802120202. () w\&-b 
enabling the student to get a good overview of the main role and functions of the PPIU, as was being given information about or access to, agency policy and procedures and to risk assessment and management procedures.

Several students did not recall receiving any induction in respect of some of these areas and just under half of the students did not recall receiving any induction in respect of their specific role within the placement setting. A minority of students indicated they had received either little or no programme of induction at all. The main issue of dissatisfaction about the process of induction appeared to centre around either the lack of understanding (as perceived by the student) from within the broader PPIU team about the social work student's role on placement, or the student's own lack of clarity about what their own role would be within the PPIU.

\section{Role perception and developing a shared understanding of roles}

Amongst students, there were mixed responses in relation to the understanding of the social work student role within the placement (and one must assume, by extension, their perception of the social work role in general). Just over half of the students felt that they had a reasonable or good understanding of their role by the end of the placement, with 5 responses categorized as representing positive placement experiences and 4 representing a more negative experience of placement. The common thread that appeared to link the differing student placement experiences, was that for placements where a social work student appeared to have had a positive placement experience, the student themselves appeared to have a relatively clear understanding of their role and believed that the PPIU staff also had a good level of understanding of their role and learning requirements. In those cases where students reported a more negative placement experience, they also reported a perceived lack of understanding by PPIU staff, of their social work student role.

\section{Positive experiences: Student view}

By the end of the placement my role within the team was well established and I had taken on a lot of responsibilities that I wouldn't have believed I would have at the beginning... my on-site supervisor's understanding of my role was very good and flexible. As the placement progressed, XXXX saw my capabilities grow and expanded the role accordingly (student 9).

13 J. of Practice Teaching \& Learning 12(2), pp.5-25. DOI: 10.1921/5802120202. ( $w \mathcal{E} b$ 


\section{Negative experiences: Student view}

My role within the PPIU by the end of placement would be described as the admin person and the IT technician. I was not really completing my key roles through the PPIU. They provided me with the opportunity to meet other agencies and it was only though them that I was able to develop my role as a student social worker. The other agencies provided me with work... (PPIU placement staff were)... unaware of my key roles and how I should be fulfilling them. I don't think they understood the amount of interaction that is needed with service users and would be wary of when I would want to start work with a service user outside of what the police interaction would normally be (student 3).

The feedback given by practice educators was relatively consistent with the range of student responses given to the same question. Both positive and negative comments were made in respect of specific PPIU placements. Where comments were negative, this appeared to be related to placements where there was a limited range of work made available to the student, where the opportunity for independent working was limited or where there was a perceived lack of understanding (within the PPIU) of the social work student role and learning requirements. The reverse was the case, in respect of the positive PPIU placement experiences.

\section{Positive experiences: Practice educator view}

Excellent learning opportunities for the students in placement. The role was clear on joint visits and investigations. In meetings i.e. case conferences the role was to share information from a police perspective and to gain an understanding of the role of social care services (practice educator 4).

Being a full member of the team; supporting police colleagues with video interviews; attending home visits, asking questions of 'victims' to ensure they are safe; to refer on to CYPS if required; to attend child protection meetings; to attend strategy meetings and report back on police intelligence; to support victims of domestic abuse to understand their predicament and the choices available to them; to complete CAF assessments; to liaise with other agencies; to work with service users (practice educator 3).

\section{Negative experiences: Practice educator view}

The student appeared more comfortable in the setting at the end of placement but continued to find it difficult to identify work undertaken independently. As PE I felt that opportunities for practice experience had been missed because the agency focus

14 J. of Practice Teaching \& Learning 12(2), pp.5-25. DOI: 10.1921/5802120202. @ w\&bb 
Is there a future for the use of non-traditional placement settings in social work?

was on providing experience of the police role (practice educator 2).

On-site supervisor view

The feedback from the 3 on-site supervisors who took part in the placement evaluation suggested that whilst these supervisors did have a clear understanding of the role of the social work student on placement, they felt there had been insufficient preparation provided for the on-site role and a lack of relevant information provided to them prior to the start of the placement. This had negatively impacted on their initial understanding of the learning requirements of the social work students. However, the poor response from on-site supervisors creates limitations for the generalisation of any themes arising from this survey, although the issues identified by the supervisors regarding insufficient preparation and lack of information is reflected in discussions of police placement settings elsewhere (Hek, 2012).

\section{The availability and suitability of learning opportunities to meet Key Roles}

Two thirds of the students placed in PPIU placements had additional learning opportunities negotiated for them within another team or agency setting outside the PPIU as part of their overall placement. This most commonly involved having some form of agreed 'attachment' to one of the local authority's children's services or adult safeguarding teams. However a range of additional learning opportunities were also accessed within voluntary and independent social work and social care organisations.

For these students, the learning opportunities were negotiated because these students had found it difficult to meet their Key Roles with the PPIU setting alone. Two thirds of the students who provided feedback, reported they had found it difficult to provide evidence of their competence in relation to Key Role 6, Demonstrate professional competence in social work practice (Topss UK Partnership, 2002) within the PPIU setting alone. Between one third and just over one half of the students respectively, also found it difficult to meet Key Roles 4 (Manage risk to individuals, families, carers, groups, communities, self and colleagues) and Key Role 5 (Manage and be accountable, with supervision and support, for your own social work practice within your organisation) within the PPIU placement setting alone (ibid).

Where learning opportunities were provided outside of the PPIU, these

15 J. of Practice Teaching \& Learning 12(2), pp.5-25. DOI: 10.1921/5802120202. ( $w \& b$ 
were variable in nature and duration. Some students were offered a series of 'one off' meetings or specific opportunities to shadow social workers or other professionals working in partner agencies. Other students were linked for much longer lengths of time directly with specific social work teams for anything from a 7 day block placement, up to and including a regular attachment to a social work team of 1 or 2 days per week (undertaking joint casework alongside a social worker) for up to 50 to $70 \%$ of the total duration of the placement. In all cases where additional learning opportunities were negotiated outside the PPIU, the off-site practice educator maintained their role and felt they were clear about who was responsible for the supervision and assessment of the student's work in relation to these learning opportunities.

\section{Learning points}

It is clear that the range and complexity of work provided within different PPIUs was inconsistent and the opportunities for independent working in some PPIUs, were limited. This was similar to the experiences of social work students placed in other police settings (Hek, 2012). The lack of independent work (beyond shadowing and joint working with police officers) may have contributed to the value placed by students on learning opportunities accessed outside the PPIU, particularly in gaining some local authority social work experience. However, these forms of 'blended placements' (Scholar et al., 2012) were very much the result of the student, on-site supervisor and practice educator being proactive in making direct contact with the local social work teams and negotiating a 'bespoke' arrangement for each individual student during the course of the 100 day placement, rather than there being a more strategic or pre-planned approach to provision of these additional learning opportunities across all PPIU placements. These additional learning opportunities were therefore reliant on the goodwill of the social work staff within local authority teams in being willing to offer support and appropriate work to the student. The process of negotiating, agreeing and setting up these arrangements (considering important issues such as accountability, for example) were also time consuming for all parties involved in the placement.

The importance of additional work for students outside of PPIUs and the linking in of students to social work agencies outside the PPIU 'as part

16 J. of Practice Teaching \& Learning 12(2), pp.5-25. DOI: 10.1921/5802120202. @ $w \& b b$ 
and parcel of the placement' has been noted elsewhere (Hek, 2012; Roberts and McMillan, 2008). This arrangement, as a method of enhancing the student experience, has also been made in relation to social work student placements in other non-traditional settings, often as an integral part of the placement (Wilson and Hillison, 2005 and Gregson and Fielding, 2008) and planned and agreed at the initial stages of the placement. Whilst the positive benefits of placements within non-traditional settings still stand, where such complementary work with social work settings has not been arranged, it has been acknowledged that such arrangements can be highly beneficial to students (Barron, 2004). Scholar et al. (2012) use the term 'blended' placements, to describe such arrangements and suggest that the 'blending' of placements within and between non-traditional and statutory settings preserves and enhances the value of non-traditional settings.

\section{Areas for development}

Some of the concerns highlighted in the feedback regarding insufficient preparation (of both students and on-site supervisors) and induction, have led to some improvements being made for the current cohort of students in PPIU placements (2011-12). The police have now developed a Social Work Student Induction pack that provides detailed information about the structure, role and functions of PPIU and is now provided to all students, PPIU on-site supervisors and previous students are invited to speak to prospective final year students and all PPIU on-site supervisors are now offered 2 days training, prior to taking on responsibility for supervising a social work student. The annual workshops (attended by students, on-site supervisors, practice educators and jointly delivered by the police and the $\mathrm{HEI}$ ) continue to address understanding of the student social work role, the provision of suitable learning opportunities and are used as an information and knowledge sharing and educative opportunity for all parties involved in the placements.

However, each cohort of student placements brings new issues and whilst there are a number of benefits and positive features inherent within PPIU placements, there are still on-going issues, including (amongst on-site

supervisors and students) a continuing lack of clarity and understanding of the social work role and of the learning opportunities required within the PPIU setting. Whilst at a strategic level the need for appropriate training and support for on-site supervisors has been accepted, there is a question

17 J. of Practice Teaching \& Learning 12(2), pp.5-25. DOI: 10.1921/5802120202. @ w\&b 
as to whether this has yet filtered down or is seen as a priority, at the local or individual PPIU team level. The current political climate of resource constraints and increasing pressures on staff time may be a contributory factor here.

\section{Ways forward}

Despite the considerable amount of time and effort invested in developing these PPIU placements, there is an imminent and more serious debate to be had in terms of the future viability of using such placements for final year social work students and these considerations also have potential implications for all current final year placements in all types of nontraditional settings.

The Social Work Task Force (2009) commented that initial social work education and training was not reliable in 'preparing students for the demands of frontline practice' (p.16) and therefore proposed that all students should be offered

at least one placement in a local authority, mental health trust or national organisation undertaking statutory work' (p.23).

This proposal has since been taken forward through the work of the Social Work Reform Board (SWRB) and The College of Social Work (TCSW) and it is now suggested that the final placement 'must prepare students for the statutory aspects of a social workers role' (SWRB, 2011, p.35).

The link that is implied here - between a 'statutory' placement or intervention and the degree of 'preparedness' for statutory practice - is not unequivocally confirmed by further research and reports (Carpenter et al., 2010; Sharpe, et al., 2011). In their evaluation of the first year of the Newly Qualified Social Worker Programme (NQSW), Carpenter et al. (2010) found that the majority of NQSWs working in children's services found the first year much busier than they had expected, whether these NQSWs had qualified as social workers through employment based routes or by undertaking their final placement in the organisation where they were employed as NQSWs. This was despite the fact that the NQSWs who qualified through employment based routes generally had a better understanding of the employing organisations policies and procedures and the team workload. This evaluation suggests that frontline social work

18 J. of Practice Teaching \& Learning 12(2), pp.5-25. DOI: 10.1921/5802120202. @ $w \mathcal{E} b$ 
in busy statutory teams with safeguarding and procedural demands are a 'shock' for all, regardless of previous work or final placement experience. Sharpe et al. (2011), in a study of social work graduates who have moved into the workforce, noted however, that three quarters of first year graduates actually felt well prepared for their job by their degree studies. Many of these new graduates were going into child protection work in statutory settings without having had a placement opportunity in child protection. Whilst 'the ideal for many managers was for their newly qualified member of staff to have undertaken a placement in exactly the same setting... they would already be familiar with processes, if not precise, procedures' (Sharpe et al., 2011, p.93), only one fifth of employed graduates had been recruited through being on placement with that employer. Sharpe et al. (2011) noted that the question of 'preparedness' for practice was open to interpretation. Whilst employers required 'functionally ready workers needing little help to fulfil their tasks in the workplace' (p.12), HEI's saw their role as developing critical and reflective practitioners who are competent on the verge of qualification but who will continue to develop their knowledge and mature their skills during their careers. This latter view is encapsulated in the Professional Capabilities Framework (PCF), the new developmental framework for the social work profession which provides guidance regarding progression between capability levels and career stages at all levels - from entry (to the end) of qualifying social work degree programmes; progression in the qualified social work role, moving on to the managerial, professional educator and advanced practitioner pathways at Advanced level (TCSW, 2012c).

In relation to social work student placements, the new 'Practice learning guidance - Placement criteria' states that the setting selected for the last placement (of 100 days) 'should be defined by the tasks undertaken by students on placement, rather than the setting (e.g. local authority) or type of placement (e.g. statutory)' (TCSW, 2012a, p.2). The learning opportunities must therefore allow the student to demonstrate engagement with a series of tasks relevant to certain aspects of the PCF (e.g. PCF 1, 5, 6,7 and 8). This includes formal assessment processes and consideration of risk; application and understanding of legal frameworks relevant for social work practice; multiagency working, including planning interventions with other agencies; analysing and managing tensions and use of formal agency recording for assessment/risk (TCSW, 2012a). Whilst many of these requirements could potentially be met within PPIU placements, if provided in a 'blended form' alongside experience within local authority statutory

19 J. of Practice Teaching \& Learning 12(2), pp.5-25. DOI: 10.1921/5802120202. ๑ wEb 
Cathie Jasper, Liz Munro, Pauline Black and Hugh McLaughlin

teams, the guidelines for last placement additionally state that:

If the practice educator is not on-site, the student will work alongside a social worker, who must be in a post requiring social work registration. This social worker will take day-to-day responsibility for the supervision of the student. In order to support the development of professional identity, students should not be the sole social work representative in a setting (TCSW, 2012a, p.3).

It is clear that this additional criterion impacts greatly on the future viability of using PPIU placements for last placements. PPIU placements do not have registered social workers as on-site supervisors (although of course the off-site practice educators are experienced and registered social workers.) Although the Practice Educator Professional Standards and Guidance (TCSW 2012b) states that there may be 'exceptional circumstances' (p.18) where the placement supervisor is not a registered social worker, in such situations,

the student must have the additional support of working alongside a social worker in a post requiring social work registration in order to undertake the required statutory tasks (TCSW 2012a, p.18).

Even if PPIU placements were further developed to become more formally 'blended placements' (Scholar et al., 2012) incorporating work within a local authority (statutory) setting, the current placement criteria guidelines for last placement (TCSW,2012a) do not offer sufficient clarity in relation to them. This is despite the current national practice learning context of on-going difficulties regarding the supply of statutory placements and the capacity of some of these placements to offer high quality learning experiences (McNay, 2008). With the national proportion of statutory placements continuing to decline, constituting $54 \%$ of all placements in 2009-10 (GSCC, 2012, p.7), the suggestion that statutory employers are committed to providing placements is within a context characterised by increasing pressure, restructuring, reduced funding and staffing issues (GSCC, 2012). Within some local authorities currently providing placements in the North West of England, the Staff Development and Training officers who have overseen the development and allocation of social work student placements within the local councils have been victim to restructuring - some posts have disappeared or seen the "practice education' element within them decreased. This is at a time when employers

20 J. of Practice Teaching \& Learning 12(2), pp.5-25. DOI: 10.1921/5802120202. @ $w \& b b$ 
are also being expected to meet a comprehensive range of requirements developed to support implementation of the central recommendations of the Social Work Task Force (SWTF, 2009), including Practice Educator Professional Standards; the Assessed and Supported Year in Employment; Continuing Professional Development and the Standards for Employers of Social Workers in England and Supervision Framework (SWRB, undated).

In the light of the new placement criteria for last placement (TCSW, 2012a), we believe that using the PPIU placements as practice learning opportunities for final placements may be no longer viable. We are instead assessing their suitability for use as a first placement. However, the nature of the work and learning opportunities provided within PPIU settings including high levels of risk, child protection, domestic violence and elder abuse issues; the detailed understanding and application of legislation; inter professional working in sometimes contested arenas - would appear to exceed the PCF narrative level descriptors for the end of the first placement which advises that students should demonstrate effective use of knowledge, skills and values 'in predominantly less complex situations' (TCSW, 2012c, p.4). The level of understanding, confidence and judgement required to maximise learning and opportunities in these PPIU settings may therefore be too great for many first placement students.

Alongside the current national drive towards prioritising 'statutory' placement criteria for last placement, there is a contrasting shift taking place in models of social service delivery characterised by a move away from publicly provided social work services towards a "modern system of social care ... including prevention, partnerships and plurality' (Sharpe et al, 2011, p.149). Sharpe et al. (2011) therefore suggest a degree of 'caution against the assumption that social work qualifying education is simply about preparing graduates to work in statutory social work settings' (p.149).

Despite the current moves towards ensuring all final year social work practice learning opportunities should be predominantly defined by the statutory role of social work, this does not in itself guarantee the achievement a good quality learning environment (Bellinger, 2010). In good quality practice learning environments 'practice is constructed rather than prescribed' (Bellinger, 2010, p.2461) and non-traditional placement settings through blended placements, can offer the ideal opportunity for students to explore more creative ways of working. It does therefore seem ironic that in a climate of continuing shortages of final level placements, in the context of the development of more pluralistic models of delivery (Samuel, 2012) and at a time when the holistic nature of social work is being

21 J. of Practice Teaching \& Learning 12(2), pp.5-25. DOI: 10.1921/5802120202. ๑ w\&b 
'reclaimed' through the implementation of the PCF (TCSW, 2012c), that the opportunity to further develop 'blended placements' for final year social work students using non-traditional placement settings, may well be lost.

\section{References}

Barron, C. (2004) Fair play: Creating a better learning climate for social work students in social care settings. Social Work Education, 23, 25-37

Bell, J. (1993) Doing Your Research Project: A guide for First-Time Researchers in Education and Social Science. (2nd ed.) Buckingham: Open University Press

Bellinger, A. (2010) Talking about (Re) Generation: Practice learning as a site of renewal for social work. British Journal of Social Work, 40, 8, 2450-2466

Billingham, J. (1999) Developing and sustaining practice placements in small voluntary agencies. Social Work Education, 18, 3, 335-345

Braun, V. and Clarke, V. (2006) Using thematic analysis in psychology. Qualitative Research in Psychology, 3, 77-101

Bryman, A. (2008) Social Research Methods. (3rd ed.) Oxford: Oxford University Press

Carpenter, J., Mc Laughlin, H., Patsios, D., Blewett, J., Platt, D., Scholar, H., Tunstill, J., Wood, M., and Shardlow, S. (2010) Newly Qualified Social Worker Programme: Evaluation report on the first year: 2008-09. Leeds: Children's Workforce Development Council [Online] [Accessed on 10/06/12] Available from: www.cwdcouncil.org.uk/assets/0001/1071/NQSW_Y1_ Evaluation_print_copy.pdf

Collins, D., Blewett, J., Manthorpe, J. and Tarr, S. (2010) Social work practice learning in schools: Lessons for practice. Practice, 22, 2, 89-101

Doel, M. (2005) New Approaches to Practice Learning. London: Practice Learning Taskforce

Doel, M., Deacon, L., and Sawdon, C. (2007) Curtain down on act one: Practice learning in the first year of the new Social Work Award, Social Work Education, 26, 3, 217-232

Department of Health (2002) Requirements for Social Work Training. London: Department of Health [Online] [Accessed on 10/06/12] Available from: http://www.dh.gov.uk/en/Publicationsandstatistics/Publications/ PublicationsPolicyAndGuidance/DH_4007803

General Social Care Council (2004) Code of Practice for Social Care Workers and Code of Practice for Employers of Social Care Workers. London: General Social

22 J. of Practice Teaching \& Learning 12(2), pp.5-25. DOI: 10.1921/5802120202. @ w\&bb 
Care Council [Online] [Accessed on 10/06/12] Available from: http://www. gscc.org.uk/page91/Get+copies+of+our+codes.html

General Social Care Council (2009-10) A Report on Social Work Education in England: Data pack. London: General Social Care Council [Online] [Accessed on 10/06/12] Available from: http://www.gscc.org.uk/cmsFiles/Education\%20 and\%20Training/SWEG\%20Publications/A_Report_on_Social_Work_ Education_in_England_2009-10_Full_Data.pdf

General Social Care Council (2012) The Supply of Social Work Practice Placements: Employers' views, London: General Social Care Council [Online] [Accessed on 10/06/12] Available from: http://www.gscc.org.uk/cmsFiles/News\%20items/ GSCC_The_supply_of_social_work_practice_placements_research_report. pdf

Gregson, L. and Fielding, J. (2008) Student social workers in school settings: A practice assessor's perspective. The Journal of Practice Teaching in Health and Social Work, 8, 1, 91-101

Hek, R (2012) Is it possible to develop and sustain non-traditional placements? An evaluation of the development of practice learning opportunities in partnership with the Police and Probation Services in the West Midlands, Social Work Education, 31, 4, 512-529

Hughes, M. (2009) Development and implementation of social work practice learning opportunities in NHS settings with no previous experience of social work education. The Journal of Practice Teaching in Health and Social Work, 9, $1,20-45$

Maclean, S. and Caffrey, B. (2009) Quality Factors in Social Work Practice Learning: the North West experience,. Leyland: Skills for Care North West [Online] [Accessed on 10/06/12] Available from: http://www.skillsforcare.org.uk/ home/searchResults.aspx?cx=014323292036356581376\%3Aru5ssyo6ut8 \&ie $=U T F-8 \&$ output $=x m l \& s t a r t=0 \& a s \_s i t e s e a r c h=w w w . s k i l l s f o r c a r e . o r g$. $\mathrm{uk} \& \mathrm{q}=$ Maclean\& $\& \mathrm{~s}=\&$ $=\&$ iteurl=www.skillsforcare.org. $\mathrm{uk} \% 2 \mathrm{Fpublications} \% 2 \mathrm{~F}$ publications_q.aspx\&ref=www.skillsforcare.org.uk\%2Fpublications\%2Fpub lications_m.aspx

McNay, M. (2008) Evaluation of the New Social Work Degree Qualification in England: Executive summary. London: Department of Health [Online] [Accessed on 10/06/12] Available from: http://www.dh.gov.uk/prod_consum_dh/groups/ dh_digitalassets/@dh/@en/documents/digitalasset/dh_087159.pdf

Miller, A. (2007) The Keys to Success: Developing practice learning in Police and Prison Services in the West Midlands. Birmingham: Skills for Care West Midlands [Online] [Accessed on 14/06/12] Available from: http://www.skillsforcare.org. uk/publications/area_publications_archive.aspx

23 J. of Practice Teaching \& Learning 12(2), pp.5-25. DOI: 10.1921/5802120202. ๑ w\&b 
Orme, J. and Shemmings, D. (2010) Developing Research Based Social Work Practice. Basingstoke: Palgrave Macmillan

Roberts, D. and McMillan, J. (2008) Unlocking Doors : Keys to sustained success - the further development of practice learning opportunities within police and prison settings in the West Midlands region. Birmingham: Skills for Care West Midlands [Online] [Accessed on 14/06/12] Available from: http://www.skillsforcare.org. uk/publications/area_publications_archive.aspx

Samuel, M. (2012) Social work outside the town hall: Special report. Community Care [Online] [Accessed on 24/5/12] Available from: http://www.communitycare. co.uk/social-work-outside-the-local-authority/

Scholar, H., McCaughan, S., McLaughlin, H. and Coleman, A. (2012) 'Why is This not social work?' The Contribution of 'non-traditional' placements in preparing social work students for practice. Social Work Education,31, 7, 932-950

Sharpe, E; Moriarty, J; Stevens, M; Manthorpe, J and Hussein, S (2011) Into the Workforce: Report from a study of new social work graduates funded under the Department of Health Social Care Research Initiative. London: Sharpe Research; Social Care Workforce Research Unit, King's College London. [Online] [Accessed on 10/06/12] Available from: http://www.kcl.ac.uk/sspp/departments/sshm/ scwru/dhinitiative/projects/sharpeetal201litwfinalreport.pdf

Social Work Task Force (2009) Building a safe, Confident Future: The final report of the Social Work Task Force. London: Department for Children, Schools and Families [Online] [Accessed on 10/06/12] Available from: https://www.education.gov. uk/publications/standard/publicationdetail/pagel/DCSF-01114-2009

Social Work Reform Board (undated) Standards for Employers of Social Workers in England and Supervision Framework [Online] [Accessed on 11/06/12] Available from: http://www.collegeofsocialwork.org/uploadedFiles/TheCollege/_ CollegeLibrary/Reform_resources/standards-for-employers(em1).pdf

Social Work Reform Board (2011) Improving the Quality and Consistency of Initial Qualifying Social Work Education and Training. London: Department for Education [Online] [Accessed on 10/06/12] Available from: http:// www.collegeofsocialwork.org/uploadedFiles/TheCollege/Media_centre/ Improving $\% 20$ the $\% 20$ quality $\% 20$ and $\% 20$ consistency $\% 20$ of $\% 20$ initial $\% 20$ qualifying\%20social\%20work\%20education\%20and\%20training\%20final.pdf

The College of Social Work (2012a) Practice Learning Guidance: Placement criteria (edref9). London: TCSW [Online] [Accessed on 10/06/12] Available from: http:// www.collegeofsocialwork.org/resources/reform-resources/

The College of Social Work (2012b) Practice Educator Professional Standards and Guidance (edref11). London: TCSW [Online] [Accessed on 10/06/12] Available from: http://www.collegeofsocialwork.org/resources/reform-resources/

24 J. of Practice Teaching \& Learning 12(2), pp.5-25. DOI: 10.1921/5802120202. @ w\&bb 
Is there a future for the use of non-traditional placement settings in social work?

The College of Social Work (2012c) Understanding What the Different Levels Mean in the PCF. London: TCSW [Online] [Accessed on 10/06/12] Available from: http://www.education.gov.uk/swrb/a0074240/professional-standards-forsocial-workers-in-england

Topss UK Partnership (2002) National Occupational Standards for Social Work. Leeds: Topss England [Online] [Accessed on 10/06/12] Available from: http://www. skillsforcare.org.uk/developing_skills/National_Occupational_Standards/ social_work_NOS.aspx

Wilson and Hillison, L. and Hillison, K. (2005) Back to school for social work students: Developing quality practice learning opportunities in schools. Journal of Practice Teaching in Health and Social Work, 6, 43-60 